\title{
Pulmonary hypertension due to left heart disease
}

\author{
Jean-Luc Vachiéry ${ }^{1}$, Ryan J. Tedford ${ }^{2}$, Stephan Rosenkranz ${ }^{3}$, \\ Massimiliano Palazzini ${ }^{4}$, Irene Lang ${ }^{5}$, Marco Guazzi ${ }^{6}$, Gerry Coghlan ${ }^{7}$, \\ Irina Chazova ${ }^{8}$ and Teresa De Marco 9
}

Number 9 in the series

"Proceedings of the 6th World Symposium on Pulmonary Hypertension"

Edited by N. Galiè, V.V. McLaughlin, L.J. Rubin and G. Simonneau

\begin{abstract}
Affiliations: ${ }^{1}$ Dept of Cardiology, Cliniques Universitaires de Bruxelles - Hôpital Erasme, Brussels, Belgium. ${ }^{2}$ Division of Cardiology, Dept of Medicine, Medical University of South Carolina (MUSC), Charleston, SC, USA. ${ }^{3}$ Clinic III for Internal Medicine, Dept of Cardiology, Heart Center at the University of Cologne and Cologne Cardiovascular Research Center (CCRC), University of Cologne, Cologne, Germany. ${ }^{4}$ Dept of Investigational, Diagnostic and Specialty Medicine, Bologna, Italy. ${ }^{5}$ Dept of Cardiology, AKH-Vienna, Medical University of Vienna, Vienna, Austria. ${ }^{6}$ Dept of Biomedical Sciences for Health, University of Milan and Dept of Cardiology University, IRCCS Policlinico San Donato, San Donato Milanese, Milan, Italy. ${ }^{7}$ Dept of Cardiology, Royal Free Hospital, London, UK. ${ }^{8}$ Russian Cardiology Research Complex, Moscow, Russia. ${ }^{9}$ University of California, San Francisco, CA, USA.
\end{abstract}

Correspondence: Jean-Luc Vachiéry, Dept of Cardiology, Cliniques Universitaires de Bruxelles - Hôpital Erasme, 808 Route de Lennik, 1070 Brussels, Belgium. E-mail: jeanluc.vachieryderasme.ulb.ac.be

@ERSpublications

State of the art and research perspectives in pulmonary hypertension due to left heart disease including diagnostic and treatment insights http://ow.ly/vr0I30md6KC

Cite this article as: Vachiéry J-L, Tedford RJ, Rosenkranz S, et al. Pulmonary hypertension due to left heart disease. Eur Respir J 2019; 53: 1801897 [https://doi.org/10.1183/13993003.01897-2018].

ABSTRACT Pulmonary hypertension (PH) is frequent in left heart disease (LHD), as a consequence of the underlying condition. Significant advances have occurred over the past 5 years since the 5th World Symposium on Pulmonary Hypertension in 2013, leading to a better understanding of PH-LHD, challenges and gaps in evidence. $\mathrm{PH}$ in heart failure with preserved ejection fraction represents the most complex situation, as it may be misdiagnosed with group $1 \mathrm{PH}$. Based on the latest evidence, we propose a new haemodynamic definition for PH due to LHD and a three-step pragmatic approach to differential diagnosis. This includes the identification of a specific "left heart" phenotype and a non-invasive probability of PH-LHD. Invasive confirmation of PH-LHD is based on the accurate measurement of pulmonary arterial wedge pressure and, in patients with high probability, provocative testing to clarify the diagnosis. Finally, recent clinical trials did not demonstrate a benefit in treating PH due to LHD with pulmonary arterial hypertension-approved therapies. 


\section{Introduction}

Pulmonary hypertension (PH) is a common complication of left heart disease (LHD), in response to a passive increase in left-sided filling pressures, more specifically left atrial pressure [1]. It is currently defined as post-capillary $\mathrm{PH}$, by an increase in mean pulmonary arterial pressure (mPAP) $\geqslant 25 \mathrm{mmHg}$ and a pulmonary arterial wedge pressure (PAWP) $>15 \mathrm{mmHg}$ [2]. In most cases, PH-LHD (group $2 \mathrm{PH}$ ) is a consequence or an abnormal biomarker of the underlying cardiac disorder. However, the structure and function of the pulmonary circulation may be further affected by several mechanisms potentially leading to pulmonary arterial and venous remodelling. In heart failure, recent data even suggest that the severity of PH correlates most strongly with venous and small arteriolar intimal thickening [1-3]. In addition, the function of the right ventricle is often affected independently from the afterload increase [4-7], leading to uncoupling of the right ventricle/pulmonary artery unit [8-10] with further exercise limitation and adverse outcome. This is especially true in heart failure with preserved ejection fraction (HFpEF) [4-11]. Over the past 5 years since the 5th World Symposium on Pulmonary Hypertension (WSPH) in 2013, significant advances have improved our understanding of PH-LHD. This article summarises these findings, key challenges and proposals for the approach to this condition, with a specific focus on PH due to HFpEF.

\section{Definition and classification of PH-LHD}

At the 5th WSPH in 2013, a new terminology was adopted to distinguish isolated post-capillary $\mathrm{PH}$ $(\mathrm{IpcPH})$ from combined post-capillary and pre-capillary $\mathrm{PH}(\mathrm{CpcPH})$, based on the diastolic pressure difference/gradient (DPG) between the diastolic PAP (dPAP) and PAWP [1]. However, this definition was found to be too restrictive and exposed to interpretation, leading to controversies about whether the DPG would [12-15] or would not [16-21] predict outcome in patients with group $2 \mathrm{PH}$. Pulmonary vascular resistance (PVR) was subsequently reintroduced to better reflect the impact of the right ventricle on outcome [2]. To date, the haemodynamic definition of PH-LHD stands as: 1) post-capillary PH when mPAP $\geqslant 25 \mathrm{mmHg}$ and PAWP $>15 \mathrm{mmHg}$; 2) IpcPH, when DPG $<7 \mathrm{mmHg}$ and/or PVR $\leqslant 3$ Wood Units (WU); and 3) $\mathrm{CpcPH}$ when $\mathrm{DPG} \geqslant 7 \mathrm{mmHg}$ and/or PVR $>3 \mathrm{WU}$. These two distinct haemodynamic phenotypes may be further defined by several variables obtained during diagnostic right heart catheterisation (RHC), none being totally independent from potential limitations [22]. The combination of recent analyses and basic physiology reveals that the haemodynamic definition of PH-LHD relies heavily on the accurate measurement of PAWP.

\section{What is a normal PAWP and how to measure it?}

In normal individuals, PAWP is close to $\mathrm{dPAP}$, with a mean $\pm \mathrm{SD}$ value of $8.0 \pm 2.9 \mathrm{mmHg}$ [23] for a normal DPG between 0 and $2 \mathrm{mmHg}[1,2,22]$. Therefore, taking into account 2 standard deviations, a value $\geqslant 14 \mathrm{mmHg}$ should be considered abnormal. Accordingly, clinical trials in pulmonary arterial hypertension (PAH) have historically included patients with PAWP $\leqslant 15 \mathrm{mmHg}$ (in agreement with the 2016 recommendations on heart failure from the European Society of Cardiology [24]) and PVR $>3$ WU. To avoid inconsistencies, a common approach to the interpretation of the measurement is necessary. This includes timing of the measurement with respect to the cardiac and respiratory cycle, relationship with left ventricular end-diastolic pressure (LVEDP), and other confounding factors, such as the presence of large $\mathrm{v}$-waves and atrial fibrillation [25]. In the absence of mitral stenosis, PAWP measured at end-diastole (i.e. typically as the mean of the a-wave or, alternatively, a QRS-gated approach) more closely approximates LVEDP [25-27]. By contrast, the mean PAWP (averaged throughout the cardiac cycle) in the presence of large $\mathrm{v}$-waves (mitral regurgitation or non-compliant left atrium) will be higher than end-diastolic PAWP and will overestimate LVEDP. This contributes to negative DPG values reported in many studies and may also be observed in atrial fibrillation, when no a-wave is present [28-31]. Since the $\mathrm{v}$-wave contribution may augment the systolic PAP (sPAP), using the end-diastolic PAWP rather than mean PAWP may lead to a slight overestimation of PVR in the aforementioned scenarios.

\section{Recommendations for measurement of PAWP/LVEDP in the differential diagnosis of PH}

- A value of PAWP $>15 \mathrm{mmHg}$, measured at end-expiration at rest, is considered consistent with PH-LHD. There is insufficient new data since the 5th WSPH in 2013 to recommend a change in this cut-off value.

- PAWP should be measured at end-diastole to determine the pre-capillary component of PH-LHD and the calculation of PVR. In sinus rhythm, this corresponds to the mean of the a-wave. In atrial fibrillation, it is appropriate to measure PAWP $130-160 \mathrm{~ms}$ after the onset of QRS and before the v-wave.

- There are no new data to suggest a change in standards for the measurement of PAWP. Therefore, we continue to recommend the assessment of PAWP at end-expiration, as averaging over of the respiratory cycle would reclassify many post-capillary $\mathrm{PH}$ patients to pre-capillary disease with the current PAWP cut-off value. 
- Best practice suggests that RHC should be performed in stable, non-acute clinical conditions for the differential diagnosis of $\mathrm{PH}$. Proper levelling at the mid-chest and "zero"ing the transducer to atmospheric pressure are critical. Patients should be positioned supine with legs flat and pressures recorded during spontaneous breathing (no breath-hold). Measurements should be repeated in triplicate to obtain values within a $10 \%$ agreement.

- If PAWP is elevated and the accuracy of PAWP is in question, blood oxygen saturation should be determined in the wedge position. If the PAWP oxygen saturation is $<90 \%$, direct LVEDP measurement should be obtained.

- The presence of significant, large v-waves should be noted as this strongly suggests LHD regardless of resting PAWP.

\section{How to define CpcPH?}

Evidence in PH-LHD has been generated since the 5th WSPH in 2013 to 1) characterise the clinical profile, 2) describe the haemodynamic features and 3) identify outcome predictors. Indeed, the presence and the identification of a pre-capillary component in post-capillary $\mathrm{PH}$ are critical as it may have an impact on prognosis, can modify management and serves as the basis for clinical trial design [32]. In addition, $\mathrm{CpcPH}$ is associated with a reduced exercise capacity and a phenotype similar to PAH [21, 33]. Finally, it has been recently suggested that $\mathrm{CpcPH}$ may present a genetic profile that could be different from IpcPH [16].

Nevertheless, the populations studied in these retrospective registries are heterogeneous, from pure heart failure with reduced ejection fraction (HFrEF) cohorts [16-18], all causes of LHD [12, 15, 20, 21, 28, 34], to pure valvular heart disease (VHD) registries $[13,14]$. The typical profile of PH-LHD combines an elevated PAWP (>20 mmHg), a mildly elevated mPAP $(25-40 \mathrm{mmHg})$, a low cardiac index $\left(\leqslant 2.5 \mathrm{~L} \cdot \mathrm{min}^{-1} \cdot \mathrm{m}^{-2}\right)$, an elevated transpulmonary pressure gradient (TPG) $(>12 \mathrm{mmHg})$, a normal DPG $(<3 \mathrm{mmHg})$ and PVR ranging from 3 to $4.9 \mathrm{WU}$. In addition, right atrial pressure is consistently elevated ( $>10 \mathrm{mmHg}$ ), which may, together with elevated PAWP, suggest fluid overload or pericardial constraint. Finally, most studies reported a significant proportion (roughly one-third) of negative DPG that may be explained by the aforementioned limitations [27]. This is in keeping with a high rate of atrial fibrillation, affecting around $40 \%$ of patients.

The search for an ideal predictor of outcome in PH-LHD has led to conflicting results. On multivariate analysis, several predictors were found: a combination of mPAP and PVR $[13,16]$, pulmonary arterial compliance (PAC) either alone [19, 20] or in combination with MPAP and PAWP [16], or a combination of mPAP and DPG [12]. A meta-analysis identified 10 retrospective analyses using PVR, DPG and/or PAC to predict survival in PH-LHD [35]. For the purpose of consistency, and to better individuate the risk associated with each variable, independently of arbitrary cut-offs, only studies reporting the prognostic power of continuous variables were included. The analysis was done on a total of 2513 patients, followed for up to 15 years. The haemodynamic profile revealed average values of mPAP, PVR, DPG and PAC of $35 \mathrm{mmHg}, 3.0 \mathrm{WU}, 1.2 \mathrm{mmHg}$ and $2.5 \mathrm{~mL} \cdot \mathrm{mmHg}^{-1}$, respectively. In this analysis, DPG, PVR and PAC appeared to be associated with survival. However, both PVR and PAC were stronger predictors of outcome when compared with DPG [35]. It was suggested that a combination of variables might be better than an isolated value for prognosis purposes [35]. Interestingly, a recent analysis of three large US cohorts showed that higher pulmonary artery elastance and lower PAC are associated with increased mortality and right ventricular dysfunction, across the spectrum of heart failure and even when resistive load was normal [36]. This strongly suggests that, in $\mathrm{CpcPH}$ due to heart failure, the total right ventricular load is closely linked to outcome. Finally, a recent large retrospective analysis of 2587 patients with $\mathrm{PH}-\mathrm{HFpEF}$ showed that TPG $\geqslant 12 \mathrm{mmHg}$, PVR $\geqslant 3 \mathrm{WU}$ and $\mathrm{DPG} \geqslant 12 \mathrm{mmHg}$ were predictors of mortality and heart failure hospitalisations [37].

Therefore, the best way to describe the pre-capillary component of post-capillary $\mathrm{PH}$ remains controversial; none of the haemodynamic variables proposed to describe PH-LHD [22] are free from limitations.

\section{Recommendations}

- After careful consideration of the changes in the general definition of $\mathrm{PH}$ [36], the proposed haemodynamic definition of PH in LHD is: 1) IpcPH: PAWP $>15 \mathrm{mmHg}$ and $\mathrm{mPAP}>20 \mathrm{mmHg}$ and $\mathrm{PVR}<3 \mathrm{WU}$; and 2) CpcPH: PAWP $>15 \mathrm{mmHg}$ and $\mathrm{mPAP}>20 \mathrm{mmHg}$ and PVR $\geqslant 3 \mathrm{WU}$.

- Beyond a strict haemodynamic definition, other markers of disease may be taken in consideration to better determine a patient's prognosis. These could include an additional haemodynamic marker (e.g. DPG or PAC), cardiopulmonary exercise testing (CPET) profile (level of $V^{\prime} \mathrm{E} / V^{\prime} \mathrm{CO}_{2}$ (minute ventilation/oxygen uptake) slope, exercise oscillatory ventilation, end-tidal carbon dioxide tension 
$\left.\left(P \mathrm{ETCO}_{2}\right)\right)$, indices of right ventricular function and right ventricle/pulmonary artery coupling (compliance and elastance) and biomarkers. In the context of $\mathrm{PH}$ due to HFpEF, ST2, a member of the interleukin-1 superfamily, may be complementary to $\mathrm{N}$-terminal pro-brain natriuretic peptide (NT-proBNP) [24].

- Given the limitations of pure haemodynamic definitions, future studies should be aimed at developing biomarkers and other non-haemodynamic diagnostics to discriminate IpcPH and $\mathrm{CpcPH}$.

\section{Diagnostic approach and differential diagnosis of PH-LHD}

Although RHC is the gold standard for the diagnosis of $\mathrm{PH}$, it is not sufficient to make a clear distinction between idiopathic PAH (IPAH) and PH-LHD, especially when risk factors or documented history of cardiovascular disease (CVD) coexist $[1,2,32,34,38]$. Therefore, we propose a three-step approach to the differential diagnosis: 1) identification of a clinical phenotype to establish the characteristics of group $2 \mathrm{PH}, 2$ ) determination of a pre-test probability to identify which patients should move to an invasive evaluation and 3) haemodynamic characterisation, which could include provocative testing in selected cases.

\section{Clinical phenotype of PH due to LHD}

The revised clinical classification distinguishes three main entities in group $2 \mathrm{PH}$ [38]: 1) $\mathrm{PH}$ due to HFpEF, 2) PH due to HFrEF and 3) PH due to VHD. In contrast to the other aetiologies, the distinction between PH due to HFpEF, PAH and chronic thromboembolic PH (CTEPH) may be challenging. Indeed, traditional cardiovascular risk factors may be present in patients with $\mathrm{PAH}[32,34,39]$. Patients with systemic sclerosis may present with left ventricular involvement, independent from the presence of $\mathrm{PH}$ and pulmonary vascular disease (PVD) [40]. In patients with CTEPH, PAWP may be difficult to measure due to pulmonary artery obstruction and LVEDP may be elevated as patients may have concomitant cardiac involvement [41]. Finally, patients with HFpEF [32] and PH due to HFpEF [42] may present with a low diffusing capacity of the lung for oxygen (DLCO), an independent predictor of outcome [43]. All these potential confounding factors may lead to misclassification of $\mathrm{PH}$.

The latter may be avoided by combining factors that are typically associated with group $2 \mathrm{PH}$, which include clinical features, echocardiographic abnormalities and other tests (e.g. magnetic resonance imaging and CPET) [1, 2, 39]. Interestingly, the prevalence of such risk factors in the COMPERA registry is high, particularly in an older subgroup of patients with cardiovascular comorbidities (referred to as "atypical $\mathrm{PAH}^{\prime}$ ) and in patients with $\mathrm{PH}$ due to HFpEF [34]. Importantly, a high rate of atrial fibrillation was reported at the time of diagnosis in IPAH, "atypical PAH" and PH due to HFpEF, in 10\%, $42 \%$ and 54\%, respectively.

\section{Pre-test probability of PH due to LHD}

As a single variable will unlikely be sufficient for accurate differential diagnosis, a combination of the previous features may help to determine a pre-test probability of group $2 \mathrm{PH}$. Composite scores integrating clinical and non-clinical features were derived from retrospective single-centre analyses [44-48], lacking external validation. A proposal to integrate these features is shown in table 1, some being markers of high probability of PH-LHD (previous cardiac interventions, presence of atrial fibrillation at diagnosis, evidence for structural LHD and CPET abnormalities). This approach is in line with the current strategy for the general diagnosis of PH $[2,49]$ and has also recently been suggested in the assessment of HFpEF [50].

\section{Haemodynamic evaluation of PH-LHD}

As a general rule, the decision for invasive confirmation of PH-LHD assumes the presence of an intermediate to high probability of $\mathrm{PH}$ based on symptoms and echocardiographic features, following the revised diagnostic algorithm [51]. In patients with a high probability of LHD as a cause of PH, the general management should be guided according to the recommendation for the underlying condition. In patients with an intermediate probability, invasive characterisation may be performed in patients with risk factors for PAH (e.g. systemic sclerosis), CTEPH or in cases of unexplained dyspnoea. The presence of right ventricular abnormalities also requires invasive assessment as it may have an influence on management (figure 1a). Due to the presence of multiple confounding factors and the complexity of the interpretation of invasive measurements, RHC should be performed in expert centres [2]. Provocative testing during RHC may be useful in the distinction between healthy subjects and HFpEF [51-54] or to uncover PH-LHD in patients with PAWP at the upper limit of normal (ULN) (i.e. 13-15 mmHg) [55-58]. For this purpose, both exercise testing and fluid loading are used in clinical practice (table 2).

The ULN of mPAP during an incremental dynamic exercise challenge has been suggested at $>30 \mathrm{mmHg}$ with a cardiac output $(\mathrm{CO})<10 \mathrm{~L} \cdot \mathrm{min}^{-1}$, which corresponds to a total pulmonary vascular resistance $(\mathrm{TPR}=\mathrm{mPAP} / \mathrm{CO})$ of $3 \mathrm{WU}[59,60]$. The ULN of PAWP during exercise is thought to be between 15 and 
TABLE 1 Pre-test probability of left heart disease (LHD) phenotype

\begin{tabular}{|c|c|c|c|}
\hline Feature & High probability & Intermediate probability & Low probability \\
\hline Age & $>70$ years & $60-70$ years & $<60$ years \\
\hline $\begin{array}{l}\text { Obesity, systemic hypertension, } \\
\text { dyslipidaemia, glucose } \\
\text { intolerance/diabetes }\end{array}$ & $>2$ factors & $1-2$ factors & None \\
\hline Previous cardiac intervention ${ }^{\#}$ & Yes & No & No \\
\hline Atrial fibrillation & Current & Paroxysmal & No \\
\hline Echocardiography & LA dilation; grade >2 mitral flow & No LA dilation; grade $<2$ mitral flow & No LA dilation; $E / e^{\prime}<13$ \\
\hline CPET & Mildly elevated $V^{\prime} E / V^{\prime} \mathrm{CO}_{2}$ slope; EOV & Elevated $V^{\prime} E / V^{\prime} \mathrm{CO}_{2}$ slope or EOV & High $V^{\prime} E / V^{\prime} \mathrm{CO}_{2}$ slope; no EOV \\
\hline Cardiac MRI & LA strain or LA/RA $>1$ & & No left heart abnormalities \\
\hline
\end{tabular}

LBBB: left bundle branch block; LVH: left ventricular hypertrophy; RV: right ventricular; LA: left atrial; E/e': early mitral inflow velocity/mitral annular early diastolic velocity ratio; CPET: cardiopulmonary exercise testing; $V^{\prime} E$ : minute ventilation; $V^{\prime} \mathrm{CO}_{2}$ : carbon dioxide production; EOV: exercise oscillatory ventilation; MRI: magnetic resonance imaging; RA: right atrial. \#: coronary artery and/or valvular surgical and/or non-surgical procedures, including percutaneous interventions.

$25 \mathrm{mmHg}$, but higher values can be recorded in elderly subjects $[59,60]$. In addition, other factors may influence the interpretation of PAWP during exercise, including body position (supine versus upright, with supine values being $5 \mathrm{mmHg}$ higher than upright on average), age, sex, duration of exercise and timing over the respiratory cycle [60,61-64]. Many of these issues are discussed in a recent position paper [60]. Recent data suggest that initial increases in PAWP and mPAP in middle-aged healthy individuals do not necessarily reflect abnormal cardiopulmonary physiology, as pressures may normalise within minutes [61]. The ULN to detect an abnormal response of PAWP to exercise is therefore unknown. Some authors suggest a cut-off value of $25 \mathrm{mmHg}$ for the diagnosis of heart failure [51-54], although PAWP $>25 \mathrm{mmHg}$ has been found in elderly individuals free of apparent CVD [61]. Finally, different cut-offs may be used according to age and sex $[55,62,63]$. Therefore, a flow-adjusted measure of PAWP may be more appropriate than PAWP alone [59, 60], with recent work suggesting a PAWP/CO slope $>2 \mathrm{mmHg} \cdot \mathrm{L}^{-1} \cdot \mathrm{min}^{-1}$ is associated with reduced functional capacity, higher NT-proBNP and reduced heart failure-free survival [61].

As measurements of pressures during exercise are technically difficult and require specialised equipment, a fluid challenge may be easier to standardise and more readily available. Any condition associated with reduced left ventricular diastolic compliance or VHD will be associated with a rapid increase in PAWP when challenged with an increased systemic venous return [53, 54]. Although not as profound, fluid loading also increases PAWP in healthy volunteers as a function of age, sex, amount infused and infusion rate [52]. Thus, the standardisation of the test cut-off values for PAWP has raised controversies [53-55, $65,66]$. It has been shown that up to $20 \%$ of patients with pre-capillary $\mathrm{PH}$ may present an increase in PAWP $>15 \mathrm{mmHg}$ after fluid loading [56, 57, 65]. However, current evidence suggests a PAWP of 18-20 mmHg after infusion might represent the ULN (table 2) [53,66]. The advantages and limitations of exercise testing and fluid loading are presented in table 3.

\section{Recommendations}

- The nomenclature of "PAH with cardiovascular risk factors" should be preferred over any other, to account for their coexistence without suggesting that risk factors may be influencing the cause of the PVD. The role of comorbidities in the disease process of PAH is not demonstrated and remains unclear.

- A three-step approach should be followed to perform the differential diagnosis between group $2 \mathrm{PH}$ (mainly HFpEF) and PAH: 1) identification of a clinical phenotype suggesting PH-LHD, 2) determination of a pre-test probability for PH-LHD and 3) haemodynamic characterisation.

- Invasive assessment should be performed in patients with intermediate probability of PH-LHD, presence of right ventricular abnormality and when risk factors for PAH/CTEPH coexist (figure 1b).

- In patients with a PAWP $13-15 \mathrm{mmHg}$ and high/intermediate probability of PH-HFpEF, provocative testing should be considered to uncover PH due to HFpEF. For technical reasons and reliability of pressure recording, a fluid challenge is preferred over exercise in the approach to differential diagnosis.

- PAWP $>18 \mathrm{mmHg}$ immediately after administration of $500 \mathrm{~mL}$ of saline over $5 \mathrm{~min}$ is considered abnormal. 
a)

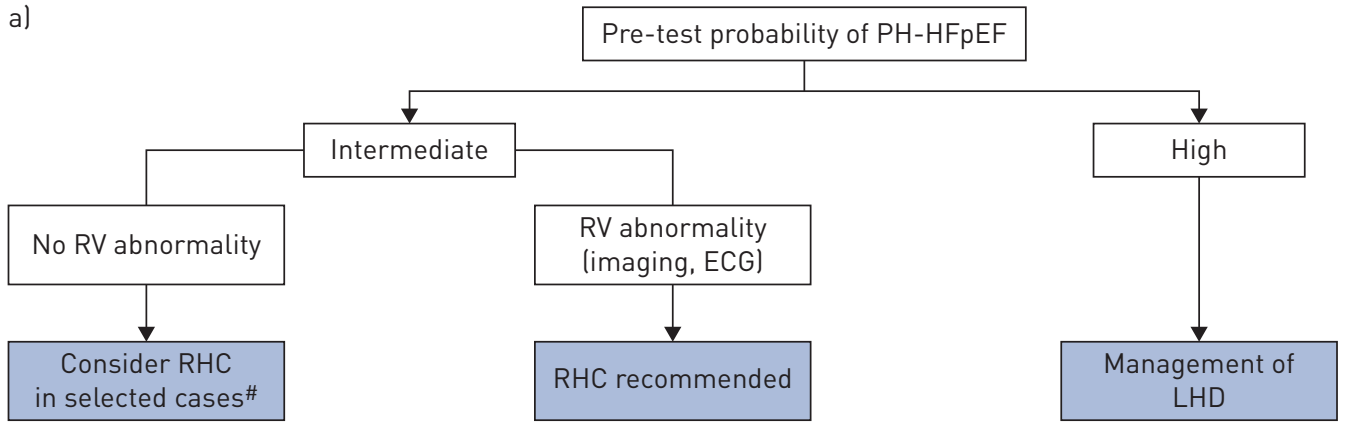

b)

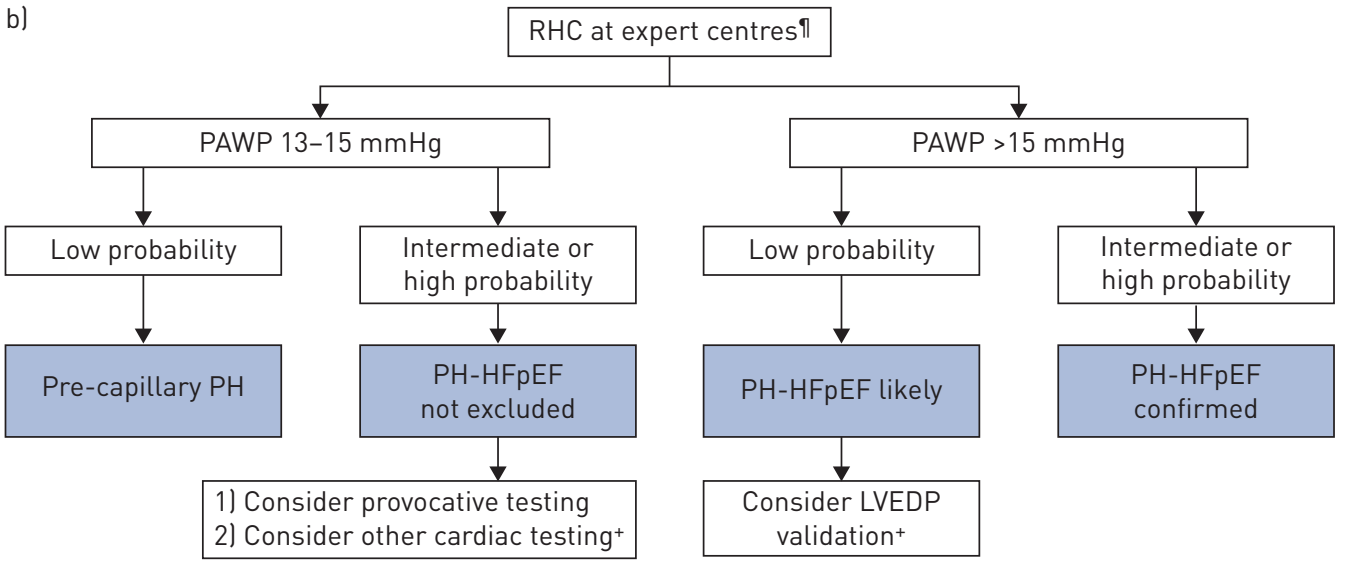

FIGURE 1 Haemodynamic assessment of pulmonary hypertension $(\mathrm{PH})$ due to heart failure with preserved ejection fraction (HFpEF). RV: right ventricular; RHC: right heart catheterisation; LHD: left heart disease; PAWP: pulmonary arterial wedge pressure; LVEDP: left ventricular end-diastolic pressure; CTEPH: chronic thromboembolic PH. a) Pre-test probability of PH-LHD is based on the features presented in table 1. RHC is recommended in intermediate probability when risk factors of pulmonary arterial hypertension/CTEPH are present and/or if there is evidence of right ventricle abnormality. If the probability is high, patients should be managed according to recommendations for LHD. b) For the assessment of PH, RHC should be performed at expert centres. In patients with intermediate/high probability (table 1) and PAWP between 13 and $15 \mathrm{mmHg}$, $\mathrm{PH}-\mathrm{HFpEF}$ is not excluded; provocative testing (tables 2 and 3) should be considered. " : for patients with systemic sclerosis, risk factors for CTEPH and/or unexplained dyspnea; ${ }^{\natural}$ : after [2]; ${ }^{+}$: if PAWP $>15 \mathrm{mmHg}$, LVEDP validation should be considered.

- However, how this should impact management is unknown. If PAH-specific therapies are initiated in patients with an "abnormal" response, caution should be exercised, including close monitoring of response and side-effects.

\section{Clinical trials and therapy for PH due to LHD}

Pathways involved in the development of PAH may contribute to the pathogenesis of heart failure and $\mathrm{PH}$ due to LHD, providing a rationale for investigating the role of their modulation in this setting $[1,2,32,39]$. Until recently, most studies were performed in HFrEF patients, leading to disappointing results [1, 2, 32, 39]. The results of the ENABLE trials with bosentan were recently published, confirming that blocking endothelin-1 has no effect on outcome in patients with HFrEF [67]. The SOCRATES programme assessed the role of vericiguat, a guanylate cyclase stimulator, in HFrEF [68] and HFpEF [69]. In SOCRATESReduced, vericiguat did not change the NT-proBNP level at 12 weeks compared with placebo [68]. Similar results were observed in SOCRATES-Preserved, with no effect on left atrial volume index, the coprimary end-point [69]. Inhaled sodium nitrite has been shown to acutely decrease left-sided filling pressures and PAP at rest [70] and exercise [71]. However, the multicentre INDIE-HFpEF trial (ClinicalTrials.gov identifier NCT02742129) did not show a benefit of the compound on exercise capacity in HFpEF after 12 weeks [72].

Since 2013, several randomised controlled trials have been completed in patients with PH-LHD (table 4). The effects of $60 \mathrm{mg}$ sildenafil 3 times a day were compared with placebo in 52 patients with $\mathrm{PH}$ due to HFpEF at 12 weeks [73]. No effect was observed on the primary end-point of mPAP, while a decrease in PVR and an improvement in exercise capacity were previously shown in a single-centre trial [74]. Riociguat, a guanylate cyclase stimulator, did not improve mPAP after 12 weeks in patients with PH due to HFrEF [75]. 
TABLE 2 Pulmonary arterial wedge pressure (PAWP) response to exercise in normal and heart failure with preserved ejection fraction (HFpEF), and response to fluid loading in normal, HFpEF and pulmonary hypertension (PH)

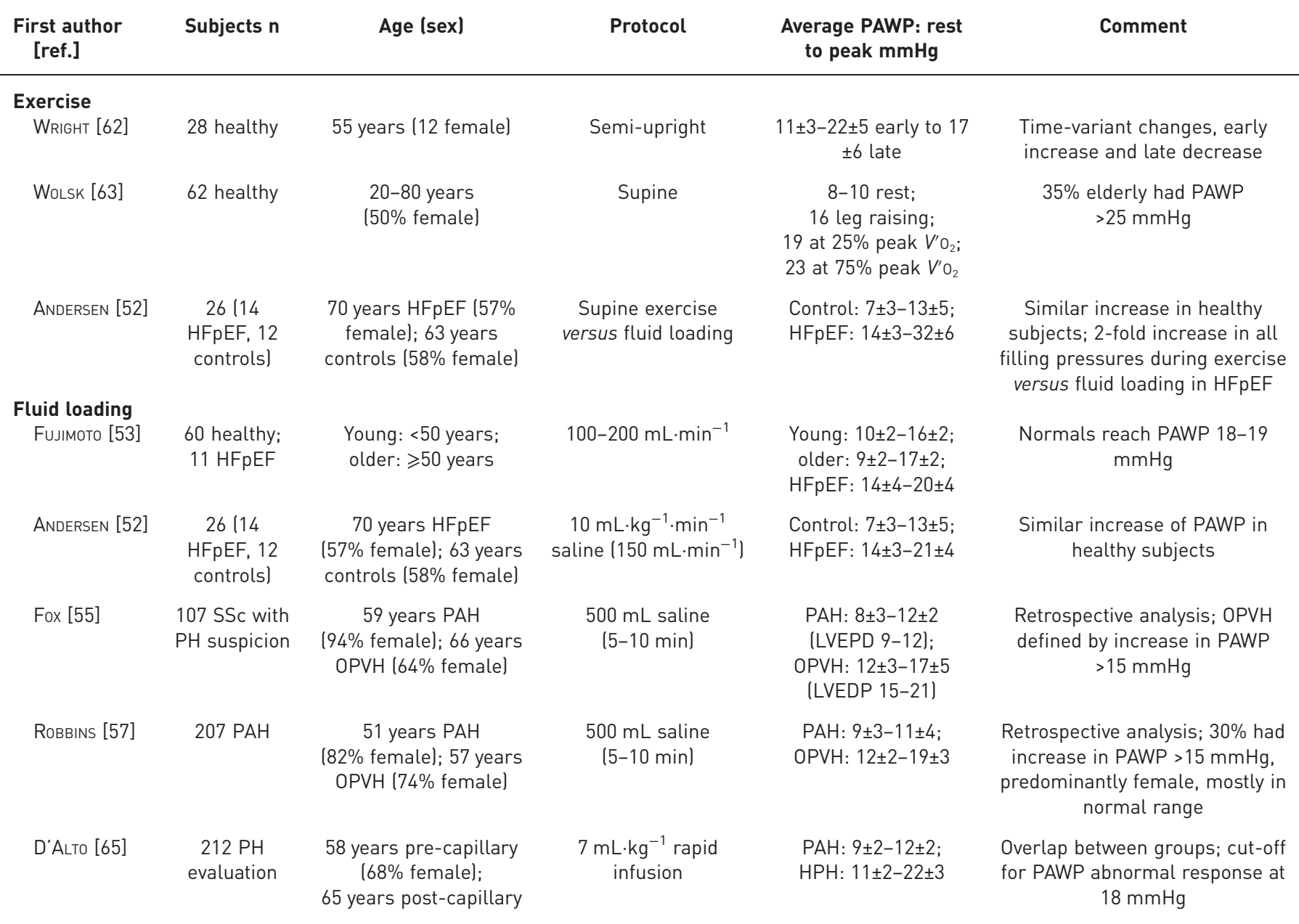

$V^{\prime} \mathrm{O}_{2}$ : oxygen uptake; SSc: systemic sclerosis; PAH: pulmonary arterial hypertension; LVEDP: left ventricular end-diastolic pressure; OPVH: occult pulmonary venous hypertension (defined as PAWP >15 mmHg after fluid loading); $\mathrm{HPH}$ : hidden pulmonary hypertension due to left heart disease.

The MELODY-1 study was the only study specifically including patients with $\mathrm{CpcPH}$ [76]. Patients were randomised to placebo or macitentan $10 \mathrm{mg}$. The main end-point assessed a composite of significant fluid retention (weight gain $\geqslant 5 \%$ or $\geqslant 5 \mathrm{~kg}$ because of fluid overload or parenteral diuretic administration) or worsening in New York Heart Association Functional Class (NYHA FC) from baseline to end of treatment. Exploratory end-points included changes in NT-proBNP and haemodynamics at week 12. Treatment with macitentan was associated with a $10.1 \%$ increased risk of fluid retention versus placebo, mostly within the first month. At week 12, the macitentan group showed no change in PVR, mean right atrial pressure or PAWP with respect to placebo.

Finally, the SIOVAC trial aimed to determine whether treatment with sildenafil improves outcomes of patients with persistent PH after correction of VHD [77]. Patients who had undergone a successful valve replacement or repair procedure at least 1 year before inclusion were randomised to $40 \mathrm{mg}$ sildenafil 3 times daily $(\mathrm{n}=104)$ versus placebo $(\mathrm{n}=96)$ for 6 months. The primary end-point was a composite clinical score combining death, hospital admission for heart failure, change in NYHA FC and patient global self-assessment. Improvement in the clinical score was significantly more frequent in the placebo group (44 versus 27 patients receiving sildenafil). In contrast, worsening was more common in the sildenafil group (33 versus 14 patients in the placebo group). The Kaplan-Meier estimates for survival without admission due to heart failure were 0.76 and 0.86 in the sildenafil and placebo group, respectively, although this did not reach statistical significance.

The typical profile of patients included in the trials modulating the nitric oxide/cGMP pathway shows an elderly (70 years) female predominance, with a high rate of atrial fibrillation at baseline (44-77\%) and 
TABLE 3 Limitations and advantages of exercise testing and fluid loading in the assessment of pulmonary hypertension

Exercise testing

$+++$

Clinical relevance for symptom assessment

Clinical relevance for differential diagnosis Main advantages

Main limitations

Standardised protocol
Respects the pathophysiology; comprehensive test, allowing for additional insights in pulmonary vascular disease (dynamic pulmonary vascular resistance); complementary with cardiopulmonary exercise testing

Requires a specific complex setting; expertise in conducting the test; pressure reading during exercise; range of normal response uncertain

+ +-
Fluid loading

Easy to perform, no specific setting; minimal risk of misinterpretation of pressures reading; better established cut-off defining abnormal increase in pulmonary arterial wedge pressure

Unknown response in disease state; age dependency of response

$++$

preserved ejection fraction in more than half of the cases. With the exception of the MELODY trial, patients had IpcPH, as shown by a combination of DPG around $2 \mathrm{mmHg}$ and PVR below or slightly above $3 \mathrm{WU}[73,75,77]$. In contrast, the patients recruited in the MELODY trial had a typical CpcPH profile, which was associated with higher baseline NT-proBNP, reflecting worse right ventricular function [76]. Several studies using PAH therapies/pathways in PH-LHD are underway (table 5).

\section{$\mathrm{PH}$ and vasoreactivity testing in end-stage heart failure}

In the context of heart transplantation, $\mathrm{PH}$ is associated with an increased 30-day mortality in patients with TPG $>15 \mathrm{mmHg}$ and PVR $>5 \mathrm{WU}$ [78]. A continuous risk of morbidity and mortality increases with progressive elevation in mPAP, TPG and PVR [79]. Finally, PH reverses soon after heart transplantation, the most pronounced reduction in PVR occurring within 1 month post-transplant [80]. Implantation of a left ventricular assist device (LVAD) rapidly reduces "fixed" $\mathrm{PH}$ in heart transplant candidates, with survival outcomes comparable to patients without [81]. In addition, right ventricular afterload almost always declines with LVAD insertion and does so rapidly [82]. It is therefore recommended to perform RHC in all candidates before listing and at 3-6-month intervals in listed patients, especially in the presence of reversible $\mathrm{PH}$ or worsening heart failure [83]. LVAD recipients with at least one post-implant RHC without PH likely require less frequent assessments [84]. The current recommendations for heart transplantation suggest that an acute vasodilator challenge should be performed if sPAP $>50 \mathrm{mmHg}$, and either TPG $\geqslant 15 \mathrm{mmHg}$ or PVR $>3 \mathrm{WU}$ and systemic systolic arterial pressure $>85 \mathrm{mmHg}$ [83]. However,

TABLE 4 Recently completed randomised controlled trials targeting the phosphodiesterase type 5 inhibitor/nitric oxide and endothelin pathways in pulmonary hypertension due to left heart disease

\begin{tabular}{|c|c|c|c|c|c|c|c|}
\hline $\begin{array}{l}\text { First author or } \\
\text { study [ref.] }\end{array}$ & $\begin{array}{l}\text { Study } \\
\text { drug }\end{array}$ & Dose & $\begin{array}{c}\text { Subjects } \\
n\end{array}$ & Duration & Population & Primary outcome & Result \\
\hline GuAZZI [74] & Sildenafil & $\begin{array}{c}50 \mathrm{mg} \\
3 \text { times a day }\end{array}$ & 44 & 12 months & HFpEF & $\begin{array}{c}\text { PVR, } \\
\text { RV performance, } \\
\text { CPET }\end{array}$ & Improvement \\
\hline LEPHT [75] & Riociguat & $\begin{array}{l}0.5,1 \text { or } 2 \mathrm{mg} \\
3 \text { times a day }\end{array}$ & 201 & 16 weeks & HFrEF & $\begin{array}{l}\text { mPAP versus } \\
\text { placebo }\end{array}$ & No change \\
\hline SIOVAC [77] & Sildenafil & $\begin{array}{c}40 \mathrm{mg} \\
3 \text { times a day }\end{array}$ & 231 & 24 weeks & VHD & $\begin{array}{c}\text { Composite clinical } \\
\text { score }{ }^{\#}\end{array}$ & $\begin{array}{c}\text { Worsening in active } \\
\text { group }\end{array}$ \\
\hline MELODY-1 [76] & Macitentan & $\begin{array}{c}10 \mathrm{mg} \\
\text { once daily }\end{array}$ & 48 & 12 weeks & $\begin{array}{l}\text { HF (EF >30\%); } \\
75 \% \text { HFpEF }\end{array}$ & $\begin{array}{l}\text { Safety and } \\
\text { tolerability }\end{array}$ & $\begin{array}{l}+10 \% \text { fluid retention } \\
\text { in active group }\end{array}$ \\
\hline
\end{tabular}

HF: heart failure; pEF: preserved ejection fraction; PVR: pulmonary vascular resistance; RV: right ventricular; CPET: cardiopulmonary exercise testing; rEF: reduced ejection fraction; mPAP: mean pulmonary arterial pressure; VHD: valvular hear disease. \#: combination of death, hospitalisation for HF, change in New York Heart Association Functional Class and patient global self-assessment. 
TABLE 5 Planned and ongoing trials in pulmonary hypertension (PH) due to left heart disease

\begin{tabular}{|c|c|c|c|c|c|c|}
\hline Study ${ }^{\#}$ & Study drug & Dose & $\begin{array}{l}\text { Subjects } \\
n\end{array}$ & Duration & Population & Primary outcome \\
\hline $\begin{array}{l}\text { SERENADE } \\
\text { (NCT03153111) }\end{array}$ & Macitentan & $\begin{array}{c}10 \mathrm{mg} \\
\text { once daily }\end{array}$ & 300 & 52 weeks & $\begin{array}{c}\text { LVEF } \geqslant 40 \% \text { and ESC-defined } \\
\text { HFpEF; HF hospitalisation within } \\
12 \text { months and/or PAWP or } \\
\text { LVEDP }>15 \mathrm{mmHg} \text { within } \\
6 \text { months; elevated NT-proBNP; } \\
\text { PVD or RVD }\end{array}$ & $\begin{array}{l}\% \text { change from baseline in } \\
\text { NT-proBNP at week } 24\end{array}$ \\
\hline $\begin{array}{l}\text { DYNAMIC } \\
\text { (NCT02744339) }\end{array}$ & Oral riociguat & $\begin{array}{c}1.5 \mathrm{mg} \\
3 \text { times a day }\end{array}$ & 114 & 26 weeks & $\begin{array}{c}\text { HFpEF; mPAP > } 25 \mathrm{mmHg} \text { and } \\
\text { PAWP >15 mm }\end{array}$ & Change in $\mathrm{CO}$ \\
\hline $\begin{array}{l}\text { Oral treprostinil } \\
\text { (NCT03037580) }\end{array}$ & $\begin{array}{l}\text { Oral } \\
\text { treprostinil }\end{array}$ & & 310 & 24 weeks & $\begin{array}{l}\text { LVEF } \geqslant 50 \% \text {; RHC within } 90 \text { days } \\
\text { of randomisation; } 6 \mathrm{MWD}>200 \mathrm{~m}\end{array}$ & $\begin{array}{l}\text { Change in 6MWD from } \\
\text { baseline to week } 24\end{array}$ \\
\hline
\end{tabular}

\#: ClinicalTrials.gov identifier numbers are provided where possible. LVEF: left ventricular ejection fraction; ESC: European Society of Cardiology; HF: heart failure; pEF: preserved ejection fraction; PAWP: pulmonary arterial wedge pressure; LVEDP: left ventricular end-diastolic pressure; NT-proBNP: N-terminal pro-brain natriuretic peptide; PVD: pulmonary vascular disease; RVD: right ventricular dysfunction; LVAD: left ventricular assist device; RHC: right heart catheterisation; PVR: pulmonary vascular resistance; mPAP: mean pulmonary arterial pressure; CO: cardiac output; 6MWD: 6-min walk distance; NA: not available.

there is no specific recommendation on the agent to be used. Outside of this setting, the role of vasoreactivity testing does not clearly predict outcome in PH-LHD [1, 2, 20]. Finally, there is a paucity of evidence supporting the use of $\mathrm{PAH}$-approved therapies in patients awaiting heart transplantation and/or LVAD.

\section{Recommendations}

- There is still no multicentre trial that suggests targeting PH-LHD with PAH-specific drugs is beneficial. Therefore, we maintain a strong recommendation against the use of $\mathrm{PAH}$ therapies in group $2 \mathrm{PH}$.

- In addition, a safety signal should be acknowledged: 1) the use of sildenafil in the context of $\mathrm{PH}$ post-VHD intervention is associated with an increased risk of clinical deterioration and death, and 2) the use of macitentan in $\mathrm{CpcPH}$ due to heart failure is associated with an increased risk of fluid retention.

- Following the MELODY-1 trial, new standards have been proposed to explore the role of $\mathrm{PAH}$-approved therapies in the context of group $2 \mathrm{PH}$. If pursued, such trials should be limited to $\mathrm{PH}$ due to HFpEF with $\mathrm{CpcPH}$. The agent of choice should ideally be a HFpEF disease-modifying drug. Finally, a proof-of-concept study should be performed first, with safety and tolerability, haemodynamic and/or CPET efficacy end-points.

- Vasoreactivity testing is not recommended in patients with PH-LHD, outside of the context of assessment for heart transplantation.

\section{Conclusions}

$\mathrm{PH}$ is common in LHD; it is not a disease, although a subset of patients present with significant pulmonary vascular changes. Clinical research and prospective long-term multicentre analysis of PH-HFpEF cohorts may help to better identify risk factors for $\mathrm{CpcPH}$ and provide insights on outcome predictors. A pre-test probability assessment of LHD should be part of the diagnostic approach of $\mathrm{PH}$. Further studies are needed to develop a multidimensional prediction score. Invasive confirmation on RHC requires attention to accurate resting PAWP measurement, at end-diastole and end-expiration. An increase of PAWP $>18 \mathrm{mmHg}$ after fluid loading, in patients with resting values between 13 and $15 \mathrm{mmHg}$ and 
intermediate/high probability of HFpEF, may be considered abnormal. However, we strongly encourage further study of this population as well as non-haemodynamic, alternative strategies to differentiate IpcPH and $\mathrm{CpcPH}$. The $\mathrm{CpcPH}$ haemodynamic presentation is now defined by $\mathrm{PVR}>3 \mathrm{WU}$ on top of a post-capillary $\mathrm{PH}$ phenotype. Finally, multicentre randomised trials using PAH therapies in PH-LHD have not demonstrated benefit and have raised safety concerns. Their use is still not recommended in PH-LHD.

Conflict of interest: J-L. Vachiéry reports consultancy and speaker fees paid to institution, and is an investigator in clinical trials for Actelion Pharmaceuticals and Bayer, consultancy fees paid to institution from Novartis, and consultancy fees paid to institution, and is an investigator in clinical trials for Sonivie and Pfizer, during the conduct of the study; consultancy fees paid to institution, and is an investigator in clinical trials for Arena Pharmaceuticals, Bial Portela and Sonivie, consultancy and speaker fees paid to institution, and is an investigator in clinical trials for GSK and Pfizer, consultancy fees and travel grants paid to institution from MSD, and is an investigator in clinical trials for Reata, outside the submitted work. R.J. Tedford reports personal fees (Hemodynamic Core Lab) from Actelion, J\&J and Merck, and personal fees for steering committee membership from Abbott, outside the submitted work. S. Rosenkranz reports personal fees for lectures and/or consultancy from Abbott, Actelion, Arena, Bayer, BMS, MSD, Novartis, Pfizer and United Therapeutics, and institutional research grants from Actelion, Bayer, Novartis, Pfizer and United Therapeutics, outside the submitted work; and serves as chair of the Working Group "Pulmonary circulation and right ventricular function" of the European Society of Cardiology. M. Palazzini has nothing to disclose. I. Lang reports grants and personal fees from Actelion and AOP Orphan Pharma, and personal fees from Sanofi and Novartis, outside the submitted work. M. Guazzi has nothing to disclose. G. Coghlan has nothing to disclose. I. Chazova has nothing to disclose. T. De Marco reports grants from Actelion Pharmaceuticals, Pfizer, United Therapeutics, Gilead, Boston Scientific, Bellerophon, Respirex, Arena Pharmaceutical and Novartis, outside the submitted work.

\section{References}

1 Vachiéry JL, Adir Y, Barbera JA, et al. Pulmonary hypertension due to left heart diseases. J Am Coll Cardiol 2013; 62: D100-D108.

2 Galiè N, Humbert M, Vachiery JL, et al. 2015 ESC/ERS Guidelines for the diagnosis and treatment of pulmonary hypertension. Eur Respir J 2015; 46: 903-975.

3 Fayyaz AU, Edwards WD, Maleszewski JJ, et al. Global pulmonary vascular remodeling in pulmonary hypertension associated with heart failure and preserved or reduced ejection fraction. Circulation 2018; 137: $1796-1810$.

4 Melenovsky V, Hwang SJ, Lin G, et al. Right heart dysfunction in heart failure with preserved ejection fraction. Eur Heart J 2014; 35: 3452-3462.

5 Mohammed SF, Hussain I, AbouEzzeddine OF, et al. Right ventricular function in heart failure with preserved ejection fraction: a community-based study. Circulation 2014; 130: 2310-2320.

6 Bosch L, Lam CP, Gong L, et al. Right ventricular dysfunction in left-sided heart failure with preserved versus reduced ejection fraction. Eur J Heart Fail 2017; 19: 1664-1671.

7 Rommel KP, von Roeder M, Oberueck C, et al. Load-independent systolic and diastolic right ventricular function in heart failure with preserved ejection fraction as assessed by resting and handgrip exercise pressure-volume loops. Circ Heart Fail 2018; 11: e004121.

8 Redfield M. Heart failure with preserved ejection fraction. N Engl J Med 2016; 375: 1868-1877.

9 Andersen MJ, Hwang SJ, Kane GC, et al. Enhanced pulmonary vasodilator reserve and abnormal right ventricular: pulmonary artery coupling in heart failure with preserved ejection fraction. Circ Heart Fail 2015; 8: 542-550.

10 Borlaug BA, Kane GC, Melenovsky V, et al. Abnormal right ventricular-pulmonary artery coupling with exercise in heart failure with preserved ejection fraction. Eur Heart J 2016; 37: 3293-3302.

11 Guazzi M, Dixon D, Labate V, et al. RV contractile function and its coupling to pulmonary circulation in heart failure with preserved ejection fraction - stratification of clinical phenotypes and outcomes. JACC Cardiovasc Imaging 2017; 10: 1211-1221.

12 Gerges M, Gerges C, Pistritto AM, et al. Pulmonary hypertension in heart failure: epidemiology, right ventricular function and survival. Am J Respir Crit Care Med 2015; 192: 1234-1246.

13 O'Sullivan CJ, Wenaweser P, Ceylan O, et al. Effect of pulmonary hypertension hemodynamic presentation on clinical outcomes in patients with severe symptomatic aortic valve stenosis undergoing transcatheter aortic valve implantation: insights from the new proposed pulmonary hypertension classification. Circ Cardiovasc Interv 2015; 8: e002358.

14 Brunner NW, Yue SF, Stub D, et al. The prognostic importance of the diastolic pulmonary gradient, transpulmonary gradient, and pulmonary vascular resistance in patients undergoing transcatheter aortic valve replacement. Catheter Cardiovasc Interv 2017; 90: 1185-1191.

15 Assad TR, Hemnes AR, Larkin EK, et al. Clinical and biological insights into combined post- and pre-capillary pulmonary hypertension. J Am Coll Cardiol 2016; 68: 2525-2536.

16 Miller WL, Grill DE, Borlaug BA. Clinical features, hemodynamics, and outcomes of pulmonary hypertension due to chronic heart failure with reduced ejection fraction: pulmonary hypertension and heart failure. JACC Heart Fail 2013; 1: 290-299.

17 Tedford RJ, Beaty CA, Mathai SC, et al. Prognostic value of the pre-transplant diastolic pulmonary artery pressure-to-pulmonary capillary wedge pressure gradient in cardiac transplant recipients with pulmonary hypertension. J Heart Lung Transplant 2014; 33: 289-297.

18 Tampakakis E, Leary PJ, Selby VN, et al. The diastolic pulmonary gradient does not predict survival in patients with pulmonary hypertension due to left heart disease. JACC Heart Fail 2015; 3: 9-16.

19 Palazzini M, Dardi F, Manes A, et al. Pulmonary hypertension due to left heart disease: analysis of survival according to the haemodynamic classification of the 2015 ESC/ERS guidelines and insights for future changes. Eur J Heart Fail 2018; 20: 248-255.

20 Al-Naamani N, Preston IR, Paulus JK, et al. Pulmonary arterial capacitance is an important predictor of mortality in heart failure with a preserved ejection fraction. JACC Heart Fail 2015; 3: 467-474. 
21 Dragu R, Rispler S, Habib M, et al. Pulmonary arterial capacitance in patients with heart failure and reactive pulmonary hypertension. Eur J Heart Fail 2015; 17: 74-80.

22 Naeije R, Gerges M, Vachiéry JL, et al. Hemodynamic phenotyping of pulmonary hypertension in left heart failure. Circ Heart Fail 2017; 10: e004082.

23 Kovacs G, Berghold A, Scheidl S, et al. Pulmonary arterial pressure during rest and exercise in healthy subjects: a systematic review. Eur Respir J 2009; 34: 888-894.

24 Ponikowski P, Voors AA, Anker SD, et al. 2016 ESC Guidelines for the diagnosis and treatment of acute and chronic heart failure. Eur Heart J 2016; 37: 2129-2200.

25 Houston B, Tedford R. What we talk about when we talk about the wedge pressure. Circ Heart Fail 2017; 10: e004450.

26 Nagy AI, Venkateshvaran A, Merkely B, et al. Determinants and prognostic implications of the negative diastolic pulmonary pressure gradient in patients with pulmonary hypertension due to left heart disease. Eur J Heart Fail 2017; 19: 88-97.

27 Reddy Y, El-Sabbagh A, Nishimura R. Comparing pulmonary arterial wedge pressure and left ventricular end diastolic pressure for assessment of left-sided filling pressures. JAMA Cardiol 2018; 3: 453-454.

28 Wright SP, Moayedi Y, Foroutan F, et al. Diastolic pressure difference to classify pulmonary hypertension in the assessment of heart transplant candidates. Circ Heart Fail 2017; 10: e004077.

29 Hannah E, Smart FX, Deschamps E. Mechanisms of discrepancy between pulmonary artery wedge pressure and left ventricular end-diastolic pressure in heart failure with preserved ejection fraction. JACC Heart Fail 2018; 6: 267-269.

30 Dickinson MG, Lam CS, Rienstra M, et al. Atrial fibrillation modifies the association between pulmonary artery wedge pressure and left ventricular end-diastolic pressure. Eur J Heart Fail 2017; 19: 1483-1490.

31 Houston BA, Tedford RJ. Is pulmonary artery wedge pressure a Fib in A-Fib? Eur J Heart Fail 2017; 19: 1491-1494.

32 Hoeper MM, Lam CS, Vachiéry JL, et al. Pulmonary hypertension in heart failure with preserved ejection fraction: a plea for proper phenotyping and further research. Eur Heart J 2017; 38: 2869-2873.

33 Caravita S, Faini A, Deboeck G, et al. Pulmonary hypertension and ventilation during exercise: role of the precapillary component. J Heart Lung Transplant 2017; 36: 754-762.

34 Opitz C, Hoeper MM, Gibbs JSR, et al. Pre-capillary, combined, and post-capillary pulmonary hypertension: a pathophysiological continuum? J Am Coll Cardiol 2016; 68: 368-378.

35 Caravita S, Dewachter C, Soranna D, et al. Haemodynamics to predict outcome in pulmonary hypertension due to left heart disease: a meta-analysis. Eur Respir J 2018; 51: 1702427.

36 Tampakakis E, Shah S, Borlaug B, et al. Pulmonary effective arterial elastance as a measure of right ventricular afterload and its prognostic value in pulmonary hypertension due to left heart disease. Circ Heart Fail 2018; 11: e004436.

37 Vanderpool RR, Saul M, Nouraie M, et al. Association between hemodynamic markers of pulmonary hypertension and outcomes in heart failure with preserved ejection fraction. JAMA Cardiol 2018; 3: 298-306.

38 Simonneau G, Montani D, Celermajer DS, et al. Haemodynamic definitions and updated clinical classification of pulmonary hypertension. Eur Respir J 2019; 53: 1801913

39 Rosenkranz S, Gibbs JS, Wachter R, et al. Left ventricular heart failure and pulmonary hypertension. Eur Heart J 2016; 37: 942-954

40 Hsu S, Kokkonen-Simon KM, Kirk JA, et al. Right ventricular myofilament functional differences in humans with systemic sclerosis-associated versus idiopathic pulmonary arterial hypertension. Circulation 2018; 137: 2360-2370.

41 Kim NH, Delcroix M, Jais X, et al. Chronic thromboembolic pulmonary hypertension. Eur Respir J 2019; 53: 1801915.

42 Olson TP, Johnson BD, Borlaug BA. Impaired pulmonary diffusion in heart failure with preserved ejection fraction. JACC Heart Fail 2016; 4: 490-498.

43 Hoeper MM, Meyer K, Rademacher J, et al. Diffusion capacity and mortality in patients with pulmonary hypertension due to heart failure with preserved ejection fraction. JACC Heart Fail 2016; 4: 441-449.

44 Bonderman D, Wexberg P, Martischnig AM, et al. A noninvasive algorithm to exclude pre-capillary pulmonary hypertension. Eur Respir J 2011; 37: 1096-1103.

45 Opotowsky AR, Ojeda J, Rogers F, et al. A simple echocardiographic prediction rule for hemodynamics in pulmonary hypertension. Circ Cardiovasc Imaging 2012; 5: 765-775.

46 D'Alto M, Romeo E, Argiento P, et al. Echocardiographic prediction of pre- versus postcapillary pulmonary hypertension. J Am Soc Echocardiogr 2015; 28: 108-115.

47 Jacobs W, Konings TC, Heymans MW, et al. Noninvasive identification of left-sided heart failure in a population suspected of pulmonary arterial hypertension. Eur Respir J 2015; 46: 299-302.

48 Berthelot E, Montani D, Algalarrondo V, et al. A clinical and echocardiographic score to identify pulmonary hypertension due to HFpEF. J Card Fail 2017; 23: 29-35.

49 Frost A, Badesch D, Gibbs JSR, et al. Diagnosis of pulmonary hypertension. Eur Respir J 2019; 53 : 1801904.

50 Reddy YNV, Carter RE, Obokata M, et al. A simple, evidence-based approach to help guide diagnosis of heart failure with preserved ejection fraction. Circulation 2018; 138: 861-870.

51 Borlaug BA, Nishimura RA, Sorajja P, et al. Exercise hemodynamics enhance diagnosis of early heart failure with preserved ejection fraction. Circ Heart Fail 2010; 3: 588-595.

52 Andersen MJ, Ersboll M, Bro-Jeppesen J, et al. Exercise hemodynamics in patients with and without diastolic dysfunction and preserved ejection fraction after myocardial infarction. Circ Heart Fail 2012; 5: 444-451.

53 Fujimoto N, Borlaug BA, Lewis GD, et al. Hemodynamic responses to rapid saline loading: the impact of age, sex, and heart failure. Circulation 2013; 127: 55-62.

54 Andersen MJ, Olson TP, Melenovsky V, et al. Differential hemodynamic effects of exercise and volume expansion in people with and without heart failure. Circ Heart Fail 2015; 8: 41-48.

55 Lewis GD, Bossone E, Naeije R, et al. Pulmonary vascular hemodynamic response to exercise in cardiopulmonary diseases. Circulation 2013; 128: 1470-1479.

56 Fox B, Shimony A, Langleben D, et al. High prevalence of occult left heart disease in scleroderma-pulmonary hypertension. Eur Respir J 2013; 42: 1083-1091. 
57 Robbins IM, Hemnes AR, Pugh ME, et al. High prevalence of occult pulmonary venous hypertension revealed by fluid challenge in pulmonary hypertension. Circ Heart Fail 2014; 7: 116-122.

58 Maor E, Grossman Y, Balmor RG, et al. Exercise haemodynamics may unmask the diagnosis of diastolic dysfunction among patients with pulmonary hypertension. Eur J Heart Fail 2015; 17: 151-158.

59 Herve P, Lau EM, Sitbon O, et al. Criteria for diagnosis of exercise pulmonary hypertension. Eur Respir J 2015; 46: $728-737$.

60 Kovacs G, Herve P, Barbera JA, et al. An official European Respiratory Society statement: pulmonary haemodynamics during exercise. Eur Respir J 2017; 50: 1700578.

61 Eisman AS, Shah RV, Dhakal BP, et al. Pulmonary capillary wedge pressure patterns during exercise predict exercise capacity and incident heart failure. Circ Heart Fail 2018; 11: e004750.

62 Wright SP, Esfandiari S, Gray T, et al. The pulmonary artery wedge pressure response to sustained exercise is time-variant in healthy adults. Heart 2016; 102: 438-443.

63 Wolsk E, Bakkestrøm R, Thomsen J, et al. The influence of age on hemodynamic parameters during rest and exercise in healthy individuals. JACC Heart Fail 2017; 5: 337-346.

64 Oliveira RK, Agarwal M, Tracy JA, et al. Age-related upper limits of normal for maximum upright exercise pulmonary haemodynamics. Eur Respir J 2016; 47: 1179-1188.

65 D'Alto M, Romeo E, Argiento P, et al. Clinical relevance of fluid challenge in patients evaluated for pulmonary hypertension. Chest 2017; 151: 119-126.

66 Borlaug BA. Invasive assessment of pulmonary hypertension: time for a more fluid approach? Circ Heart Fail 2014; 7: 2-4.

67 Packer M, McMurray JJV, Krum H, et al. Long-term effect of endothelin receptor antagonism with bosentan on the morbidity and mortality of patients with severe chronic heart failure - primary results of the ENABLE Trials. JACC Heart Fail 2017; 5: 317-326.

68 Gheorghiade M, Greene SJ, Butler J, et al. Effect of vericiguat, a soluble guanylate cyclase stimulator, on natriuretic peptide levels in patients with worsening chronic heart failure and reduced ejection fraction. The SOCRATES-REDUCED randomized trial. JAMA 2015; 314: 2251-2262.

69 Pieske B, Maggioni AP, Lam CSP, et al. Vericiguat in patients with worsening chronic heart failure and preserved ejection fraction: results of the SOluble guanylate Cyclase stimulatoR in heArT failurE patientS with PRESERVED EF (SOCRATES-PRESERVED) study. Eur Heart J 2017; 38: 1119-1127.

70 Borlaug BA, Koepp KE, Melenovsky V. Sodium nitrite improves exercise hemodynamics and ventricular performance in heart failure with preserved ejection fraction. J Am Coll Cardiol 2015; 66: 1672-1682.

71 Borlaug BA, Melenovsky V, Koepp KE. Inhaled sodium nitrite improves rest and exercise hemodynamics in heart failure with preserved ejection fraction. Circ Res 2016; 119: 880-886.

72 Borlaug B, Anstrom K, Lewis G, et al. Inorganic nitrite delivery to improve exercise capacity in heart failure with preserved ejection fraction: the INDIE trial. 2018. www.abstractsonline.com/pp8/\#!/4496/presentation/41749 Date last accessed: October 15, 2018.

73 Hoendermis ES, Liu LC, Hummel YM, et al. Effects of sildenafil on invasive haemodynamics and exercise capacity in heart failure patients with preserved ejection fraction and pulmonary hypertension: a randomized controlled trial. Eur Heart J 2015; 36: 2565-2573.

74 Guazzi M, Vicenzi M, Arena R, et al. Pulmonary hypertension in heart failure with preserved ejection fraction: a target of phosphodiesterase-5 inhibition in a 1-year study. Circulation 2011; 124: 164-174.

75 Bonderman D, Ghio S, Felix SB, et al. Riociguat for patients with pulmonary hypertension caused by systolic left ventricular dysfunction: a phase IIb double-blind, randomized, placebo-controlled, dose-ranging hemodynamic study. Circulation 2013; 128: 502-511.

76 Vachiéry JL, Delcroix M, Al-Hiti $\mathrm{H}$, et al. Macitentan in pulmonary hypertension due to left ventricular dysfunction. Eur Respir J 2018; 51: 1701886.

77 Bermejo J, Yotti R, García-Orta R, et al. Sildenafil for improving outcomes in patients with corrected valvular heart disease and persistent pulmonary hypertension: a multicenter, double-blind, randomized clinical trial. Eur Heart J 2018; 39: 1255-1264.

78 Murali S, Kormos R, Uretski B, et al. Preoperative pulmonary hemodynamics and early mortality after orthotopic cardiac transplantation: the Pittsburgh experience. Am Heart J 1993; 126: 896-904.

79 Kirklin J, Naftel D, Kirklin JW, et al. Pulmonary vascular resistance and the risk of heart transplantation. J Heart Lung Transplant 1988; 7: 331.

80 Goland S, Czer LR, Kass RM, et al. Pre-existing pulmonary hypertension in patients with end-stage heart failure: impact on clinical outcome and hemodynamic follow-up after orthotopic heart transplantation. $J$ Heart Lung Transplant 2007; 26: 312-318.

81 Zimpfer D, Zrunek P, Roethy W, et al. Left ventricular assist devices decrease fixed pulmonary hypertension in cardiac transplant candidates. J Thorac Cardiovsc Surg 2007; 133: 689.

82 Masri CS, Tedford RJ, Colvin MM, et al. Pulmonary arterial compliance improves rapidly after left ventricular assist device implantation. ASAIO J 2017; 63: 139-143.

83 Mehra M, Canter CE, Hanan MM, et al. The 2016 International Society for Heart Lung Transplantation listing criteria for heart transplantation: a 10-year update. J Heart Lung Transplant 2016; 35: 1-23.

84 Houston B, Kalathiya R, Stevens GR, et al. One-and-done: do left ventricular assist device patients on the transplant list really need frequent right heart catheterization assessments for pulmonary hypertension? J Heart Lung Transplant 2015; 34: 1637-1639. 